\title{
Adverse event of antiepileptic drugs: a cross sectional study
}

\author{
$P$ A N $K$ Permatananda ${ }^{1, *}, E$ Kristin $^{2}, D$ Endharti $^{3}, R T$ Pinzon $^{2}$, and $I K$ Sumada $^{4}$ \\ ${ }^{1}$ Universitas Warmadewa Denpasar, Faculty of Medicine and Health Science, Indonesia \\ ${ }^{2}$ Universitas Gadjah Mada Yogyakarta, Faculty of Medicine, Public Health, and Nursing, Indonesia \\ ${ }^{3}$ Universitas Gadjah Mada Yogyakarta, Faculty of Pharmacy, Indonesia \\ ${ }^{4}$ Wangaya Regional Hospital Denpasar, Department of Neurology, Indonesia
}

\begin{abstract}
Epilepsy is a major non-communicable disorder. Choice between switching to another drug and combining is still debatable when the first antiepileptic drug is ineffective in controlling seizure. Polytherapy usually related with the appearance of adverse effect. This cross sectional study was conducted in Neurology Policlinic with 83 epilepsy patients, consisting of 37 patients used monotherapy and 46 patients used polytherapy. The most common adverse effect was fatigue. Statistical analysis using chi square test showed statistically significant between monotherapy and polytherapy patients against fatigue ( $\mathrm{p}$ value $<0.05$ ). In conclusion, polytherapy is related with the appearance of adverse effect in epilepsy patients.
\end{abstract}

\section{Introduction}

Epilepsy is a major non-communicable disorder reported to affect nearly 50 million populations worldwide, it is estimated that there are 55millions persons with epilepsy in India, 20 millions in USA, and 3 millions in UK [1]. Epilepsy makes up about $1 \%$ of total burden of diseases in the world (Global Burden of Disease), similar to breast cancer in women and malignancy in men, where $80 \%$ of this burden is presented in developing countries, including Indonesia [2].

In clinical practice, each patient who was diagnosed with epilepsy must be treated based on type of epilepsy. Monotherapy is currently the best pharmacotherapy option and is mandatory when first starting AntiEpileptic Drug treatment. If monotherapy is poorly tolerated or ineffective, the strategy is switching to another drug or combining [3]. In a survey conducted among European physicians from different countries the percentage that adopted an add-on AED strategy varied from $23 \%$ to $67 \%$. On the other hand a survey among epilepsy expertise in the United States, $100 \%$ of them preferred to use an alternative monotherapy after the failure of the first drug [4].

Drug combination with different mechanism of action is one of strategic methods in medical management, not only for epilepsy. However, undesirable drug interaction and difficulty in evaluating pharmacologic effect make this polytherapy method slightly dilemmatic. Older antiepileptic drugs likes phenytoin, carbamazepine, valproic acid, and phenobarbital, are notorious for their ability to produce pharmacokinetic interactions among themselves as well as with other medications via their effect on hepatic cytochrome P450 enzyme. It became recognized that combining traditional agents did not necessarily improve seizure outcome and could increase the propensity of adverse effect. Some newer antiepileptic drugs have been shown to give better pharmacokinetic profile than their older antiepileptic drugs thus raising the possibility of better tolerated drug combinations [5]. WHO defines an adverse drug effect as a response to a drug that is noxious and unintended and occurs at doses normally used in man for the prophylaxis, diagnosis, or for modification of physiological function [6]. This study aimed to assess the distribution of adverse effect related to antiepileptic treatment, as well as to monotherapy and polytherapy in tertiary referral hospital, Denpasar.

\section{Research Methods}

This study was an observational cross sectional study carried out in Neurology Department, Wangaya Regional Hospital Denpasar. Wangaya Regional Hospital is tertiary referral hospital located in capital city of Bali. Epilepsy is included in top ten diseases at Neurology Department in that hospital. All patients provided written informed consent before the study. The study was approved by the Independence Ethics Committee, Faculty of Medicine, Public Health, and Nursing, Universitas Gadjah Mada, Yogyakarta.

The adverse effect experiences of patients with epilepsy were evaluated with one structure interview, neurological and physical assessment during visit, and medical history files. The following feature of respondents were also recorded in this study: gender, age, occupation, education background, type of epilepsy, family history of epilepsy, seizure remission in last 6 months, type of treatment, duration of treatment, type of

\footnotetext{
* Corresponding author: nayakasih@gmail.com
} 
antiepileptic drug currently used, and adherence. All the data collected in neurology policlinic for 1 month.

Patients aged more than 17 years, diagnosed with epilepsy, with stable treatment for at least 3 month have good communications, could participate in this study. Severe or uncontrolled symptomatic chronic illness concomitant to epilepsy were excluded. A formal sample size calculation was not performed. All patients who met inclusion and exclusion criteria were included in this study. All data obtained will be tabulated and presented descriptively. Statistical test using chi square will be performed to see the difference in adverse effect between epilepsy patient receiving monotherapy and polytherapy.

\section{Results}

Data collection and interview were conducted for one month in October 2017. Epilepsy patients who being respondent in this study were 83 patients, consisting of 37 monotherapy and 46 polytherapy patients.

Table 1. Baseline Characteristic of Respondent.

\begin{tabular}{|c|c|c|}
\hline & Characteristic & $n(\%)(n=83)$ \\
\hline 1 & $\begin{array}{l}\text { Age } \\
-<50 \text { y.o } \\
-\geq 50 \text { y.o }\end{array}$ & $\begin{array}{l}67(80.7) \\
16(19.3)\end{array}$ \\
\hline 2 & $\begin{array}{l}\text { Gender } \\
\text { - Male } \\
\text { - Female }\end{array}$ & $\begin{array}{l}45(54.2) \\
38(45.8)\end{array}$ \\
\hline 3 & $\begin{array}{l}\text { Education } \\
\text { - Low Education } \\
\text { - High education }\end{array}$ & $\begin{array}{l}30(36.1) \\
54(65.1)\end{array}$ \\
\hline 4 & $\begin{array}{l}\text { Occupation } \\
\text { - Unemployment } \\
\text { - Working }\end{array}$ & $\begin{array}{l}44(53.0) \\
39(47.0)\end{array}$ \\
\hline 5 & $\begin{array}{l}\text { Type of epilepsy } \\
\text { - Focal } \\
\text { - Generalized }\end{array}$ & $\begin{array}{l}13(15.7) \\
70(84.3)\end{array}$ \\
\hline 6 & $\begin{array}{l}\text { Seizure Frequency before } \\
\text { treatment } \\
-<4 \mathrm{x} \\
-\geq 4 \mathrm{x}\end{array}$ & $\begin{array}{l}70(84.3) \\
13(15.7)\end{array}$ \\
\hline 7 & $\begin{array}{l}\text { Family History of } \\
\text { Epilepsy } \\
\text { - Yes } \\
\text { - No } \\
\end{array}$ & $\begin{array}{c}8(9.6) \\
75(90.4) \\
\end{array}$ \\
\hline 8 & $\begin{array}{l}\text { Seizure Remission in last } \\
6 \text { months } \\
\text { - Yes } \\
\text { - No }\end{array}$ & $\begin{array}{l}42(50.6) \\
41(49.4)\end{array}$ \\
\hline
\end{tabular}

Of 83 respondents, $59 \%$ of whom were less than 50 years old, $54.2 \%$ male, $65.1 \%$ had equal education or above high school, $53 \%$ of the respondents did not work, and $50.6 \%$ single. Based on clinical characteristic, $84.3 \%$ had generalized seizure, $84.3 \%$ had seizure less than 4 times before treatment, $90.4 \%$ had no family history of epilepsy, and $50.6 \%$ had achieved seizure remission in last 6 months (table 1). There were 37 research subjects using monotherapy and 46 research subjects using polytherapy. The most widely used monotherapy is phenytoin while the most widely used polytherapy is combination of phenytoin with clobazam. As many as $61.4 \%$ of study subjects underwent less than 10 years of therapy. All subjects had MPR score more than 80 means adhere with treatment (table 2).

Table 2. Characteristic of Therapy.

\begin{tabular}{|l|l|c|}
\hline \multicolumn{2}{|c|}{ Characteristic } & n (\%)(n=83) \\
\hline 1 & Type of treatment & \\
\hline & Monoterapy & $37(44.6)$ \\
& -Phenytoin & $24(28.9)$ \\
& -Carbamazepine & $3(3.6)$ \\
& -Valproic Acid & $10(12.0)$ \\
\hline \multirow{6}{*}{3} & \\
& Polytherapy & $46(53.4)$ \\
& -Phenytoin+clobazam & $35(42.1)$ \\
& -Carbamazepine+clobazam & $3(3.6)$ \\
& -Valproic acid+clobazam & $2(2.4)$ \\
& -Carbamazepine+valproic & $4(4.8)$ \\
& acid+clobazam & $2(2.4)$ \\
& -Phenytoin+topiramate+clobazam & \\
\hline 2 & Duration of treatment & $51(61.4)$ \\
& - $<10$ years & $32(38.6)$ \\
\hline 3 & - $\geq 10$ years & \\
& Adherence (Medication Posses & $83(100)$ \\
& Ratio) & $0(0.0)$ \\
\hline
\end{tabular}

Only 8 patients had no adverse effect and 75 patients were complaining of adverse effect after taking antiepileptic treatment, with details in table 3. The most common adverse effect is fatigue. Statistical analysis with chi square test showed statistically significant between monotherapy and polytherapy patients against fatigue as the most common adverse effect in epilepsy patients received polytherapy (table 4). Fatigue is more common in epilepsy patient received polytherapy compared to monotherapy.

Table 3. Adverse Effects Reported by Epilepsy Patients.

\begin{tabular}{|c|l|c|}
\hline No & \multicolumn{1}{|c|}{ Adverse Effect } & n (\%) (n=83) \\
\hline 1. & No adverse effect & $8(9.6)$ \\
\hline 2 & Have Adverse effect & $75(90.4)$ \\
\hline & -1 adverse effect & $29(34.9)$ \\
& -2 adverse effects & $30(36.1)$ \\
& -3 adverse effects & $14(16.9)$ \\
& -4 adverse effects & $2(2.4)$ \\
\hline \multicolumn{2}{|c|}{ Type of Adverse effects } \\
\hline 1. & Fatigue & $65(78.30)$ \\
\hline 2. & Sedation & $45(56,25)$ \\
\hline 3. & Cognitive Disturbance & $44(53.00)$ \\
\hline 4. & Blurred Vision & $39(47.00)$ \\
\hline 5 & Gingival Hyperthropy & $8(0.09)$ \\
\hline 6 & Nausea Vomiting & $4(0.05)$ \\
\hline 7 & Rash & $4(0.05)$ \\
\hline 8 & Mood Disorder & $1(0.01)$ \\
\hline
\end{tabular}


Table 4. Comparison of Adverse Effects between Monotherapy and Polytherapy.

\begin{tabular}{|c|c|c|c|c|}
\hline Variable & & Monotherapy $(n=37) n(\%)$ & Polytherapy $(n=46) n(\%)$ & $\mathrm{P}$ \\
\hline Adverse effect & $\begin{array}{l}\text { Yes } \\
\text { No }\end{array}$ & $\begin{array}{l}18(48.6) \\
19(51.4)\end{array}$ & $\begin{array}{l}27(58.7) \\
19(41.3)\end{array}$ & 0.321 \\
\hline Amount of adverse effect & $\begin{array}{l}>2 \\
\leq 2\end{array}$ & $\begin{array}{c}6(16.2) \\
31(83.8)\end{array}$ & $\begin{array}{l}10(21.7) \\
36(78.3)\end{array}$ & 0.526 \\
\hline Sedation & $\begin{array}{l}\text { Yes } \\
\text { No }\end{array}$ & $\begin{array}{l}18(48.6) \\
19(51.4)\end{array}$ & $\begin{array}{l}27(58.7) \\
19(41.3)\end{array}$ & 0.321 \\
\hline Fatigue & $\begin{array}{l}\text { Yes } \\
\text { No }\end{array}$ & $\begin{array}{l}13(35.1) \\
24(64.9)\end{array}$ & $\begin{array}{l}27(58.7) \\
19(41.3)\end{array}$ & $0.033 *$ \\
\hline Cognitive Disturbance & $\begin{array}{l}\text { Yes } \\
\text { No }\end{array}$ & $\begin{array}{c}7(18.9) \\
30(81.1)\end{array}$ & $\begin{array}{l}15(32.6) \\
31(67.4)\end{array}$ & 0.160 \\
\hline Blurred Vision & $\begin{array}{l}\text { Yes } \\
\text { No }\end{array}$ & $\begin{array}{l}14(37.8) \\
23(62.2)\end{array}$ & $\begin{array}{l}25(54.3) \\
21(45.7)\end{array}$ & 0.134 \\
\hline
\end{tabular}

*statistical test showed significant different.

\section{Discussion}

Management goal of epilepsy is to control seizure without adverse effect [7-8]. Adverse effects are a leading cause of treatment failure with antiepileptic drugs. Not only do they result in early treatment discontinuation in up to $25 \%$ patients, but also they preclude attainment of fully effective doses and have a negative effect on patient adherence [6]. Furthermore, adverse effects of antiepileptic drugs are a major source of disability, morbidity, and mortality and a substantial burden on use and cost of health care.

In this study, 37 patients used monotherapy with phenytoin as the most widely used class of antiepileptic drugs, in contrast to those in India where the most widely used conventional antiepileptic drugs are phenobarbital and valproic acid. Phenytoin is a widely used antiepileptic drug in the world and suitable for all types of epilepsy seizures, although phenytoin is no longer a first-line drug as a result of frequent side effects, but it is still widely used in poor and developing countries because of its low cost [9]. In the absence of seizure remission, drug combination becomes an option. In a retrospective study involving 1617 patients, the most commonly used combinations were lamotrignin/valproic acid, phenobarbital/phenytoin, carbamazepine/gabapentin, and carbamazepine/valproic acid [10]. The combination of phenytoin with clobazam is the most therapeutic choice obtained by the subjects. The most common combinations with clobazam are carbamazepine, valproic acid, levetiracetam, lamotrignine, and oxcarbazepine. Clobazam is a broadspectrum drug selected as an adjunct to antiepileptic drugs in epilepsy patients who do not respond to other antiepileptic drugs (focal seizures, focal seizures evolving into bilateral convulsions, and generalized seizures). Clobazam is used for a variety of reasons, first during the titration phase and waiting phases in patients requiring increased dose of antiepileptic drugs such as lamotrignine and topiramat, second in resistant epilepsy with two types of antiepileptic drugs, and the third in the case of reddish patches using first class antiepileptic drugs [11].

Adverse effects of drugs are closely related to the type of antiepileptic drugs used in the patients. All subjects used conventional antiepileptic drugs that could induce P450 cytochrome enzymes such as phenytoin, carbamazepinee, and phenobarbital or inhibit glucoronidation enzymes such as valproic acid [5]. Topiramat and Clobazam were the most commonly drug used as complement because these drugs do not induce enzymes. More than $50 \%$ of epilepsy patients in this study received clobazam in addition of their therapy that was most likely to elicit sedative adverse effects. Drowsiness followed by weakness is one of the most common complaints in patients taking clobazam. In addition to clobazam, the type of antiepileptic drugs that often trigger that adverse effects are gabapentin, levetiracetam, lamotrignin, phenobarbital, phenytoin, vigabatrin, and topiramat [12].

Psychiatric disorders in epilepsy patients are twice as high as the general population, though often undiagnosed [13]. Through this research, we found there was one epileptic patient diagnosed with mood disorder. In epileptic patients with mood disorders, it is better to avoid conventional antiepileptic drugs such as phenytoin and phenobarbital that may contribute to depression, antiepileptic medications such as lamotrigine and pregabalin are considered more appropriate [12].

Previous studies suggested that polytherapy increase the probability of adverse drug effects and reduction or elimination of polytherapy may be the way to minimize the number of adverse drug effects [14]. Subjects of this study using polytherapy reported more than 2 adverse effects slightly more frequently than those on monotherapy, but this finding was not statistically significant. We observed that adverse effect, sedation, fatigue, cognitive disturbance, and blurred vision are more frequently reported by patients treated with polytherapy, but only fatigue was statistically significant. Most of the patients used phenytoin which known to have interactions with folic acid. Phenytoin triggers the inhibition of enzymes that convert folic acid, increase folic catabolism, and inhibit the appetite center [15]. In this study, phenytoin was often combined with clobazam. Phenytoin is said to be able to release benzodiazepine-type drugs such as diazepam from a protein that binds it to inhibit its metabolism. Adverse effect as inhibitory effect from benzodizepine such as fatigue and excessive drowsiness may be occurred [5]. 
Limitation of this study includes the nonrandomized, mono center, and cross sectional study design. Since the treatment was not randomly assigned, baseline differences in disease state and possibly other factors, could be related with adverse effects, make this outcome were more likely to be occur. Observations made at one point in time do not provide information about a sequence of events and follow up. This study did not use validated questionnaire for measuring adverse effect, likes SID AED. Some subjective complaint was found during interview at polyclinic. Incomplete medical records and not all epilepsy patients undergo routine laboratory examinations so that there are likely many undiagnosed and unrecognized adverse effects happened in this research.

\section{Conclusion}

Epilepsy patient proved to report an unexpectedly high number of adverse effects, while the goal of epilepsy management is to control seizures without causing adverse effects. Some adverse effects may be related to clinical and the others may be related to medication. Fatigue was the most common adverse effects reported in this study. Using more than one type drugs usually related with the appearance of adverse effect, in this study fatigue was happened more in polytherapy than monotherapy.

We thank all medical staff at Neurology clinic at Wangaya Regional Hospital for assistance during data collection. We also thank all researchers at Pharmacology Department at Universitas Warmadewa and Universitas Gadjah Mada for helpful support and feedback on this research.

\section{References}

1. G Ranjana, S Dwajani, C Kulkarni and G R K Sarma. Acta Neurol Taiwan 22, p51-58. (2014)

2. H G Wieser, H Silfvenius. Epilepsia J 41, pS3-S9. (2000)

3. J W Sander. Epilepsia J 45, p28-34. (2004)

4. J Mani. JAPI 61, p40-43. (2013)

5. P N Patsalos, E Perucca. Lancet Neurol 2, p347354. (2003)

6. P Perucca, F G Giliam. Lancet Neurol 11, p792802. (2012)

7. C Piperidou, A Karlovasiton, N Triantafyllon, E Dimitrakoudi, A Terzoudi, E Mavraki, G Trypsiamos, K Vadikolias, I Heliopoulos, D Vassilopolous and S Balogianis. Qual Life Res. 17, p987-996. (2008)

8. J George, C Kulkarni, G R K Sarma. VIHRI 6C, p1-6. (2015)

9. S J Nevitt, A G Marson, J Weston and C T Smith. Cochrane Database Syst Rev 2, p6-10. (2017)

10. L J Stephen, M J Brodie. Seizure J 11, p349-351. (2002)
11. R Joshi, M Tripathi, P Gupta, Y K Gupta. Indian J Med Res 140, p209-215. (2014)

12. D Schmidt. Epilepsy Behav 15, p56-65. (2009)

13. O Devinski. Adv Stud Med. 3, pS669-S673. (2003)

14. B Chmielewska, K Lis, K Rejdak, M Balcerzak and B Steinborn. Arch Med Sci 9, p858-864. (2011)

15. A S Nayyar, B Nataraju and G T Subhas. J Appl Pharm Sci 02, p230-235. (2012) 